\title{
DISTRIBUTION OF TILLERS OF PLANT SPECIES IN OLD PERMANENT GRASSLAND WITH DIFFERENT TYPES OF USE ${ }^{1}$ )
}

\author{
D. M. DE VRIES and B. J. HOOGERS
}

Institute for Biological and Chemical Research on Field Crops and Herbage, Wageningen, Netherlands

\section{SUMMARY}

The combined 25 sq. $\mathrm{cm}$ specific frequency and order method $(2,3,5)$ made it possible to record the dominance tendency (Dt) of plant species in figures. The number of sampling units in which a species takes the first place in bulk divided by the total number of sampling units in which a species occurs will naturally be larger in case of strongly tillering, tussockforming species than in case of those spreading by means of stolons, rhizomes or seed.

By a research done on 1647 old permanent grasslands $(4,5)$ by means of the above mentioned method, the experience of farmers that the tillers of the weed grass Deschampsia cespitosa P.B. are spread less heterogeneously in hay-fields than in pastures, where the species forms large tufts, is confirmed. Other grasses forming intra-vaginal shoots, such as Lolium perenne L. and Dactylis glomerata L., occurred more homogeneously spread in hayfields as well.

The obvious explanation of this phenomenon is found on the one side in the ability of some grasses to form tall, little tillering hayfield types and prostrate, strongly tillering pasture types, on the other side in the fact that the tufts of rough and hairy species can develop undisturbed in pastures, because they are scarcely touched by cattle.

The fact, however, that not only tussock-forming species, but also species with long runners, such as Poa pratensis L., Agrostis stolonifera L. and Trifolium repens L. correspondingly show a difference in dispersion according to the type of use of the grassland may be taken as a passive reaction on the rough tuft-forming species, especially of the grass species Lolium perenne L. dominating in fertile pastures.

Practical experience has taught that the weed grass Deschampsia cespitosa P.B. on the one hand occurs in large tussocks in pastures and on the other hand more widely spread in hayfields (in the Netherlands it is therefore called "spreidbent"). This fact led to the investigation as to how tillers of various common herbage plants are distributed over the different types of use of grassland. This was realised by means of 1647 old permanent grasslands of all kinds chosen for plant sociological and correlative ecological research $(4,5)$.

The combined 25 sq. cm specific frequency and order method $(2,3,5)$, according to which the swards of these fields have been analysed, opened the possibility to record in figures, to what extent the separate species are distributed regularly over the sward. The number of sampling units in which the concerning species takes the first place in bulk per field (dominance frequency $=D F$ ) is divided for that purpose by the number of sampling units in which the species was found (presence frequency or frequency of occurrence, in short frequency $=$ $P F$ or $F$ ). This quotient $\frac{\mathrm{DF}}{\mathrm{PF}}$, multiplied by a 100 , has been called dominance tendency $(D t)(3,5)$. It is an adequate means to measure the irregularity of the distribution of tillers, except for cases in which an equally distributed

1) Received for publication May 11, 1959. 
species with a high PF meets with such favourable growing circumstances and has such success in the struggle for life on a field, that it is dominant practically everywhere.

The distribution of tillers is of course dependent on the way of propagation of the species. A grass species forming intra-vaginal shoots is represented by many tillers in the fully developed tussocks, while in the space between the species is of little importance. Consequently, the number of sampling units in which the species occurs, will be restricted. The measure of the sampling units being small, viz. 25 sq. $\mathrm{cm}$, the species will only dominate in it, if the sampling unit is taken from a tussock, except for cases where by chance the sampling unit is taken on the edge of the tussock. Tuft-forming species, as typical anisodisperse (heterogeneously distributed) species, will be characterized by a high Dt with a PF which usually lies considerably below a 100 per cent. Grasses forming extra-vaginal shoots, like other grassland species spreading by means of runners, whether above ground (stolons) or below ground (rhizomes), show a more regular distribution and serve more to fill up the sward. Species which do not propagate vegetatively, but by seed easily spread, like grassland herbage forming stolons or rhizomes, will naturally belong to the isodisperse (homogeneously distributed) species. In favourable circumstances they soon reach high $\mathrm{PF}$-values, contrary to which the DF remains low - except for the very tall species - resulting in an especially low Dt.

The 29 plant species mentioned here according to their average dominance tendency $(\mathrm{aDt})$ - in brackets - for all concerning fields are as follows : Deschampsia cespitosa P.B. (40.2), Festuca arundinacea Schr. (37.8), Lolium perenne L. (31.5), Dactylis glomerata L. (30.2), Holcus lanatus L. (27.1), Juncus effusus L. (26.2), Alopecurus pratensis L. (20.8), Poa annua L. (20.1), Cynosurus cristatus L. (19.8), Festuca pratensis Huds. (16.9), Phleum pratense L. (15.2), Festuca rubra L. (15.1), Anthoxanthum odoratum L. (14.5), Agrostis canina L. (14.3), Leontodon autumnalis L. (13.7), Trifolium pratense L. (13.6), Agrostis stolonifera L. (13.2), Alopecurus geniculatus L. (12.3), Agrostis tenuis Sibth. (11.8), Taraxacum officinale Weber (11.3), Agropyron repens P.B. (10.5), Poa pratensis L. (8.8), Ranunculus repens L. (8.5), Trisetum flavescens P.B. (8.1), Rumex acetosa L. (7.1), Bromus mollis L. (6.9), Poa trivialis L. (6.7), Trifolium repens L. (6.7), and Ranunculus acris L. (4.2).

As was to be expected the species known as tuft-formers such as Deschampsia cespitosa, Festuca arundinacea, Lolium perenne, Dactylis glomerata, Holcus lanatus and Juncus effusus show the highest Dt's, while species possessing rhizomes (Poa pratensis and Agropyron repens) or stolons (Trifolium repens, Poa trivialis and Ranunculus repens) or those depending on seed production for their spreading (Ranunculus acris, Bromus mollis and Rumex acetosa) are mentioned last.

It is quite apparent that the distribution of tillers not only depends on the way of propagation, but also on the type of use of the grassland. In hayfields tall and quickly growing species and so called hayfield types of grasses will become dominant in the struggle for light. This is why the sward of hayfields is more or less open. Species propagating by seed, which are able to ripen here, thus have a good opportunity to germinate. In pastures species which depend on seed production for propagation, are eliminated in a young 
stage by grazing, unless they are unpalatable for cattle. In this case species propagating vegetatively dominate, developing in this way a dense sward. Some grass species, such as Lolium perenne and Phleum pratense, are able to adjust themselves by forming many tillers and prostrate pasture types. These species will produce larger tussocks in pasture. In a sward too dense runners may even develop from intra-vaginal forming of shoots which KRUIJNE calls "shoot-raisers" (1). Large tussocks can develop also, if the cattle leaves the grass because of its roughness, as for instance with Deschampsia cespitosa.

Table 1 Average dominance tendency (aDt) with standard deviation of common grassland species with different types of use.

The number of fields concerned with the calculation of the aDt in brackets.

\begin{tabular}{|c|c|c|c|c|}
\hline & $\begin{array}{c}\text { pure } \\
\text { hayfield }\end{array}$ & $\begin{array}{l}\text { hay } \\
\text { pasture }\end{array}$ & $\begin{array}{l}\text { alternate } \\
\text { pasture }\end{array}$ & $\begin{array}{c}\text { pure } \\
\text { pasture }\end{array}$ \\
\hline on & $1+26(49)$ & $103+0.9(164)$ & $93+07(225)$ & $109+08622$ \\
\hline & & $(96)$ & 16.2 & \\
\hline grostis stolonifera & $6.9 \pm$ & $11.5 \pm 0.7(294)$ & $13.9 \pm 0.6(394)$ & $14.4 \pm 0.5(514)$ \\
\hline 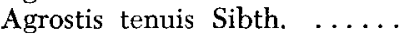 & $11.2 \pm$ & $8.9 \pm 1.2(97)$ & $10.7 \pm 1.0(156)$ & $13.6 \pm 0.7(275)$ \\
\hline arus $g$ & $5.5 \pm$ & $14.4 \pm 1.0(130)$ & $11.4 \pm 0.9(141)$ & $0.9(149)$ \\
\hline 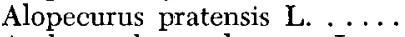 & $24.4 \pm$ & $25.3 \pm 2.1(95)$ & $17.9 \pm 1.4(113)$ & $17.2 \pm 1.8(69)$ \\
\hline domo $>$ & $11.1 \pm 1.4(92)$ & $15.6 \pm 0.7(282)$ & $15.0 \pm 0.7(297)$ & $14.5 \pm 0.8(233)$ \\
\hline & $7.0=$ & $8.3 \pm 0.8$ & $5.1 \pm 0.9(104)$ & $3.9 \pm 1.3(29)$ \\
\hline is & 17 & $19.5 \pm$ & $0(233)$ & $.9(306)$ \\
\hline & 22 & $25.9 \pm$ & $1.8(104)$ & $.4(145)$ \\
\hline & $4.7(12)$ & ( 39$)$ & $7(27)$ & $46.2 \pm 2.6(46)$ \\
\hline & $38.7=$ & $32.8 \pm$ & $38.8 \pm 5.0(19)$ & $40.3 \pm 4.7(24)$ \\
\hline $\mathrm{Fe}$ & 51) & $(255)$ & $(277)$ & $9(210)$ \\
\hline & & 12.0 & 79) & (314) \\
\hline $\mathrm{T}$ & & $29.0 \pm$ & $9(290)$ & $3(341)$ \\
\hline & & 45) & 18) & 43 \\
\hline & & $(154)$ & $(230)$ & $.9(218)$ \\
\hline & & & & $(459)$ \\
\hline & & $2(87)$ & (207) & $8(255)$ \\
\hline & & 18.6 & (98) & (218) \\
\hline & 8) & 263) & (363) & $.5(470)$ \\
\hline & & & $(416)$ & $3(494)$ \\
\hline & & $3.6=$ & 4.2 & $4(387)$ \\
\hline & & $9.0=$ & 22) & $6(331)$ \\
\hline & $9.6 \pm$ & $7.7 \pm$ & (271) & $0(121)$ \\
\hline & $8.1 \pm 1.2(48)$ & $10.9 \pm 0.6(262)$ & $\pm 0.6(349)$ & $11.5 \pm 0.6(334)$ \\
\hline & $10.6 \pm 1.8(32)$ & $16.0 \pm 1.9(76)$ & $13.5 \pm 1.3(103)$ & $12.7 \pm 1.5(81)$ \\
\hline & (47) & $4.8 \pm 0.4(333)$ & $6.9 \pm 0.4(401)$ & $8.1 \pm 0.4(513)$ \\
\hline Trisetum flaves & $3.6 \pm 0.9(27)$ & $8.0 \pm 1.2(37)$ & $10.5 \pm 1.4(78)$ & $7.0 \pm 0.9(78)$ \\
\hline
\end{tabular}

Table 1 shows the average dominance tendency with standard deviation for the species concerned and for the different types of use : pure hayfield (haying only), hay pasture (one cut of hay with grazing afterwards), alternate pasture (haying with grazing before and afterwards in some years, and grazing only in other years) and pure pasture (grazing only).

The figures of table 1 give convincing proof of the practical experience that Deschampsia cespitosa occurs more regularly distributed in hayfields than in pastures. The same happens to the other tuft-forming species Lolium perenne, Dactylis glomerata and Juncus effusus, as was to be expected. Abnormal is the lowest Dt of Juncus effusus in alternate pastures. This might be contributed to the fact that alternate pastures occur principally on clay and sandy 
clay, these soil types being not quite so poor and acid by nature as peat and sand, and usually not wet either. Consequently, the described habitat of alternate pastures is all but favourable to a vigorous growth of Juncus. Moreover alternate pastures, being a modern type of use, often have a better management. This implies an effective control of the more prominent and coarser tufts. The tall rough tuft-forming species Festuca arundinacea is an exception.

The species Alopecurus pratensis, Agropyron repens, Bromus mollis and Rumex acetosa indicating preference for hayfields have the highest Dt for that type of use, which can be explained by the great productivity there. The fact that Holcus lanatus does not behave in the same way may be explained by the circumstance that the hairy tufts of this grass are not touched by cattle later in the growing season. This favours an undisturbed development in grasslands which are indifferently grazed.

That pasture species spreading by means of long runners such as Poa pratensis, Agrostis stolonifera and Trifolium repens have Dt's which tend upwards

Table 2 Species with differences in Dt with various types of use. Reliability in difference of at least 99 per cent in normal print, of at least 95 per cent in italics. When the Dt decreases according to more grazing the name is put in brackets.

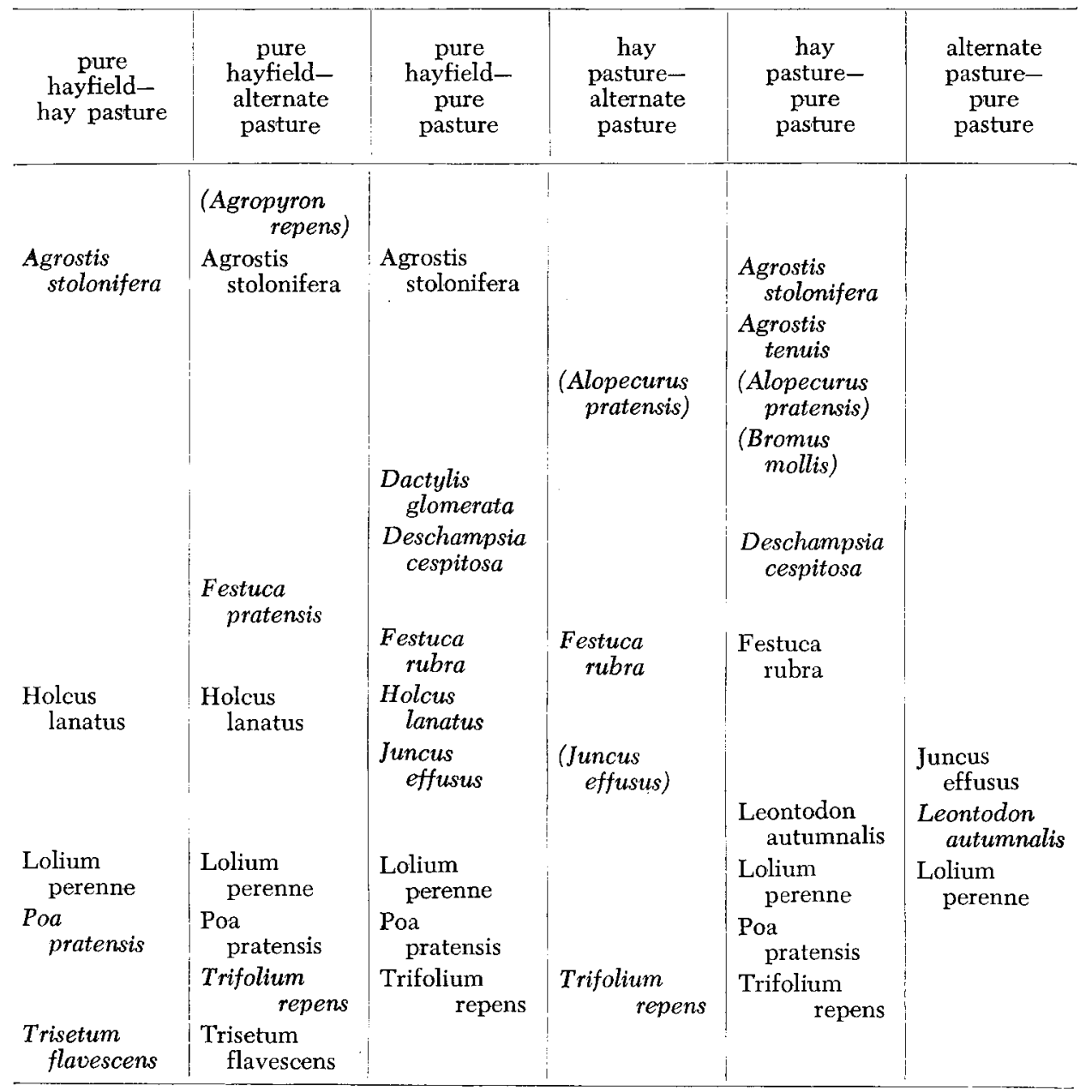


according to increased grazing, in spite of them being low, is most curious. This might be taken as a passive reaction of these species, as the dominant species Lolium perenne especially, by its dense sods, hampers them all the time in their spreading, forcing them to concentrate on the space left by the tussock-forming species. In this connection the distribution diagrams of Trifolium repens in an alternate pasture with about 30 per cent Lolium perenne and in a hay pasture with much Poa trivialis, Festuca pratensis, Alopecurus geniculatus, and without Lolium perenne should be compared (2).

The reliability og the differences in dominance tendency is indicated in table 2.

In conclusion the following may be said.

Tuft-forming grasses developing intra-vaginal shoots naturally show a higher Dt than the grasses developing extra-vaginal shoots and other herbage plants spreading by means of stolons, rhizomes or seed.

The fact already observed by farmers that Deschampsia cespitosa occurs less heterogeneously distributed in hayfields than in pastures, is confirmed. The same phenomenon can apparently be found with other grasses forming intravaginal shoots of which the tufts develop into tussocks in pastures. Widely tillering pasture types are developed in consequence of grazing, while the rough and hairy species, especially when they grow older, are not touched by cattle.

That typical pasture types spreading by means of runners are more homogeneously distributed in hayfields than in pastures is somewhat strange. The increased dominance tendency in pastures, however, should be considered as secondary. The species forming dense tussocks in pastures, amongst which especially Lolium perenne, force them to concentrate in the space left between the tussocks.

Plant species having a preference for hayfields will show a higher dominance tendency there, which should be attributed to their growth not being restricted by grazing, thus enabling them to reach a high production.

\section{BibLIOGRAPHY}

1 Kruijse, A. A. : Een morfologisch onderzoek naar de vegetatieve groei van Engels raaigras (Lolium perenne L.) (with summary: A morphological study on the vegetative growth of perennial rye-grass). Jaarboek I.B.S. 1958, (1958) 99-105.

2 VRIES, D. M. DE : Methods of determining the botanical composition of hayfields and pastures. Report of the Fourth International Grassland Congress (1937) 474-480.

3 - - : The plant sociological combined specific frequency and order method. Chronica Botanica 4 (1938) 115-117.

4 - - A. A. KRUTJNe and H. Moor: Veelvuldigheid van graslandplanten en hun aanwijzing van milieu-eigenschappen (with summary : Frequency of occurrence of herbage plants and their indication of environmental conditions). Jaarboek I.B.S. 1957 (1957) 183-191.

5 - - and TH. A. DE BoER : Methods used in botanical grassland research in the Netherlands and their application. Herbage Abstracts, Review Article, 29 (1958) 1-7. 